\title{
Validation of a handheld $\beta$-hydroxybutyrate acid meter to identify hyperketonaemia in ewes
}

\author{
Carolina Akiko Sato Cabral Araújo ${ }^{\text {Corresp., } 1}$, Antonio Humberto Hamad Minervino ${ }^{\text {Corresp., }}{ }^{2}$, Rejane Santos Sousa ${ }^{3}$, \\ Francisco Leonardo Costa Oliveira ${ }^{3}$, Frederico Augusto Mazzocca Lopes Rodrigues ${ }^{3}$, Clara Satsuki Mori ${ }^{3}$, Enrico \\ Lippi Ortolani ${ }^{3}$ \\ 1 Departamento de Medicina Veterinária, Universidade Federal Rural de Pernambuco, Recife, PE, Brazil \\ Laboratório de Sanidade Animal, LARSANA, Universidade Federal do Oeste do Pará, UFOPA, Santarem, Brazil \\ 3 Departamento de Clínica Médica, Faculdade de Medicina Veterinária e Zootecnia, FMVZ, Universidade de São Paulo, São Paulo, SP, Brazil \\ Corresponding Authors: Carolina Akiko Sato Cabral Araújo, Antonio Humberto Hamad Minervino \\ Email address: carolcbpr@gmail.com, ah.minervino@gmail.com
}

Background. The end of pregnancy is the period with the highest risk of occurrences of ketosis and pregnancy toxaemia due to fat mobilization and increasing non-esterified fatty acids in the liver which are converted in ketone bodies, mainly $\beta$-hydroxybutyrate acid (BHB). This ketone body may also become elevated in the bloodstream. The present study validates the use of a handheld meter for determining the blood concentration of BHB and ascertaining the predictive value and accuracy of BHB measurements in diagnosing hyperketonaemia in ewes.

Methods. Nineteen, non-pregnant, crossbred ewes were subjected to two hours of intravenous infusion of a saturated BHB solution. Over six hours of evaluation, 247 blood samples were obtained in 13 sampling moments. The BHB concentration was measured by an enzymatic colorimetric method in an automated biochemical analyser (gold-standard) and by a handheld meter using an electrochemical enzyme technique.

Results. There was a high correlation between both methods $(r=0.98 ; P<0.001)$. Considering the blood BHB concentrations range $0.8-1.6 \mathrm{mmol} / \mathrm{L}$ for moderate ketosis the handheld meter presented sensitivity and specificity of 0.98 and 0.81 , respectively. For severe ketosis (BHB $\geq 1.6 \mathrm{mmol} / \mathrm{L}$ ) sensitivity and specificity were 0.99 and 0.75 , respectively. Thus, the handheld device can be useful for diagnoses of cases of mild or severe pregnancy toxaemia at field conditions. 
1 Validation of a handheld ßeta-hydroxybutyrate acid meter to identify

2 hyperketonaemia in ewes

3 Carolina Akiko Sato Cabral de Araújo ${ }^{{ }^{*}}$; Antonio Humberto Hamad Minervino ${ }^{2 *}$; Rejane

4 Santos Sousa3; Francisco Leonardo Costa de Oliveira ${ }^{3}$; Frederico Augusto Mazzocca

5 Lopes Rodrigues ${ }^{3}$; Clara Satsuki Mori3 ${ }^{3}$ Enrico Lippi Ortolani ${ }^{3}$

6

$7{ }^{1}$ Departamento de Medicina Veterinária, Universidade Federal Rural de Pernambuco,

8 Recife, PE, Brazil.

9

${ }^{2}$ Laboratório de Sanidade Animal, LARSANA, Universidade Federal do Oeste do Pará,

11 UFOPA, Santarém, Pará, Brazil

${ }^{3}$ Departamento de Clínica Médica, Faculdade de Medicina Veterinária e Zootecnia,

14 FMVZ, Universidade de São Paulo, USP, São Paulo, SP, Brazil.

${ }^{*}$ Corresponding authors

17 Antonio H. H. Minervino; E-mail address: ah.minervino@gmail.com 


\section{Abstract}

23 Background. The end of pregnancy is the period with the highest risk of occurrences of

24 ketosis and pregnancy toxaemia due to fat mobilization and increasing non-esterified

25 fatty acids in the liver which are converted in ketone bodies, mainly $\beta$-hydroxybutyrate 26 acid (BHB). This ketone body may also become elevated in the bloodstream. The

27 present study validates the use of a handheld meter for determining the blood

28 concentration of $\mathrm{BHB}$ and ascertaining the predictive value and accuracy of BHB

29 measurements in diagnosing hyperketonaemia in ewes.

30 Methods. Nineteen, non-pregnant, crossbred ewes were subjected to two hours of

31 intravenous infusion of a saturated BHB solution. Over six hours of evaluation, 247

32 blood samples were obtained in 13 sampling moments. The BHB concentration was

33 measured by an enzymatic colorimetric method in an automated biochemical analyser

34 (gold-standard) and by a handheld meter using an electrochemical enzyme technique.

35 Results. There was a high correlation between both methods $(r=0.98 ; P<0.001)$.

36 Considering the blood $\mathrm{BHB}$ concentrations range $0.8-1.6 \mathrm{mmol} / \mathrm{L}$ for moderate ketosis

37 the handheld meter presented sensitivity and specificity of 0.98 and 0.81 , respectively.

38 For severe ketosis $(\mathrm{BHB} \geq 1.6 \mathrm{mmol} / \mathrm{L})$ sensitivity and specificity were 0.99 and 0.75 ,

39 respectively. Thus, the handheld device can be useful for diagnoses of cases of mild or 40 severe pregnancy toxaemia at field conditions.

41 Keywords: Pregnancy toxaemia, Sheep, Metabolic disease, Ketone bodies, Moderate 42 ketosis 


\section{Introduction}

$46 \quad$ The end of pregnancy and start of lactation are the periods of highest metabolic

47 demand and, consequently, the time of the highest risk of occurrences of ketosis and 48 pregnancy toxaemia (PT) in ewes (Ortolani \& Benesi, 1989). Pregnancy toxaemia is a 49 metabolic disease caused by a negative energy balance that result in excessive lipid 50 metabolism and ketosis (Araújo et al., 2018). Occurs generally in ewes carrying two or 51 more foetuses and has a high mortality rate (Cal-Pereyra et al., 2015b). In obese ewes, 52 the fat storage formed around the rumen predisposes the occurrence of the disease by 53 reducing dry matter intake (Lacetera et al., 2001; Araújo et al., 2018). Consequently,

54 there is a great fat mobilization in an attempt to maintain the animal's energy supply.

55 This mobilization increases initially non-esterified fatty acids in the liver that by its turn is 56 partially transformed in ketone bodies, mainly $\beta$-hydroxybutyrate acid (BHB), but also 57 acetoacetate and acetone (Radostits et al., 2007). The BHB may also become elevated 58 in the bloodstream due to mobilization of the body's reserves, especially when there is a negative energy balance in lean pregnant ewes (Radostits et al., 2007; Kalyesubula et al., 2019). Blood ketosis can also evolve to a nervous condition (nervous ketosis) caused by a BHB-derived product, the isopropanol (Araújo et al., 2014).

So far, there is no agreement about the cut off values for BHB concentrations in 63 sheep with severe PT. For severe status, some authors (Scott et al., 1995; Balikci,

64 Yildiz \& Gurdogan, 2009) consider more than $3.0 \mathrm{mmol} / \mathrm{L}$, while others more than 1.6 $65 \mathrm{mmol} / \mathrm{L}$ (Lacetera et al., 2001; Kulcsár et al., 2006) and a recent study from Uruguay pointed $2.26 \mathrm{mmol} / \mathrm{L}$ as indicative of moderate PT (Cal-Pereyra et al., 2015a). On the 
67 other hand, the authors agree that $0.8 \mathrm{mmol} / \mathrm{L} \mathrm{BHB}$ should be cut point for moderate PT

68 (Kulcsár et al., 2006; Balikci, Yildiz \& Gurdogan, 2009)

Examining the blood BHB concentrations is fundamental for detecting

70

71

72

73

74

75

76

77

78

79

80

81

82

83

84

85

86

87

88

89

hyperketonaemia in sheep and enables early diagnosis and a higher success rate in the treatment of PT (Radostits et al., 2007). Biochemical laboratory tests using commercial kits are considered to be the gold-standard (GS) for determining BHB concentrations, but semi quantitative determinations of acetoacetate and acetone in urine by Rothera's test is frequently used for diagnosing ketosis. Nevertheless, BHB determination is preferred to Rothera's test because the former gives much less false-positives results and has better accuracy (Kaneko, Harvey \& Bruss, 2008). Furthermore, BHB is more stable in blood, because it is not volatile and more abundant than the other two ketone bodies (Kaneko, Harvey \& Bruss, 2008; Benedet et al., 2020).

A handheld meter (HHM) is available for investigating ketone bodies and glycemia in human blood (Anonymous, 2007). This equipment is widely accessible, has a low cost (less than one US dollar per analysis) and the advantage of being able to quantify BHB in blood samples. Recently, it has been validated for use in dogs and cats (Hoenig, Dorfman \& Koenig, 2008), dairy cattle (Voyvoda \& Erdogan, 2010) and sheep (Panousis et al., 2012; Hornig et al., 2013). Thus, this equipment can be easily used for a practical ewe-side diagnosis of PT (Voyvoda \& Erdogan, 2010).

Previous studies that compared BHB concentrations in sheep venous whole blood measured by HHM and GS enzymatic method concluded that the BHB results did not differ between these methods (Panousis et al., 2012; Hornig et al., 2013).

Nevertheless, both studies (Panousis et al., 2012; Hornig et al., 2013) analysed BHB 
90 values from healthy sheep, with low blood BHB mean values and including limited

91 number of samples with BHB concentration greater than $3 \mathrm{mmol} / \mathrm{L}$, considered as the

92 threshold for PT (Scott et al., 1995; Balikci, Yildiz \& Gurdogan, 2009). Besides the HHM

93 was validated for early detection of blood ketosis in sheep, the studies were performed

94 with healthy animals and consequently with lower blood concentrations of BHB. Thus,

95 we aimed to validate the HHM for the measurement of BHB in sheep with a wide range

96 of blood BHB, including values corresponding to moderate and severe ketosis.

97

98 Material and methods

This research was approved by the Committee on the Ethics of Animal

100 Experiments of the School of Veterinary Medicine and Animal Science, University of 101 São Paulo (protocol 2142/2011), São Paulo, SP, Brazil.

102

103 Animals

104

Nineteen multiparous, non-pregnant, non-lactating Santa Inês crossbred ewes

105 were used. Initially, sheep underwent a 30 days adaptation period, in which they were 106 kept in collective pens. Sheep received a diet calculated as $2.7 \%$ of body weight $(\mathrm{kg}$ dry

107 matter/d), which consisted of 50\% coast-cross (Cynodon dactylon) hay and $50 \%$

108 commercial concentrate (Fri-Ovinos 22/70, Nutreco Nutrição Animal, Pitangueiras, SP,

109 Brazil). (2.7\%). Their mean \pm standard deviation (SD) body weight was $50.9 \pm 4.2 \mathrm{~kg}$ at 110 the beginning of the study, after the adaptation period. Ewes were weighted weekly to 111 correct the diet accordingly. The chemical composition of the diet is presented at Table 112 1. All animals had water and mineral mixture ad libitum. 


\section{Study design}

Sheep were subjected to a protocol for inducing hyperketonaemia adapted from

116 the model described elsewhere (Schlumbohm \& Harmeyer, 2003) to obtain samples

117 with different concentrations of $\mathrm{BHB}$. Before the BHB infusion, the animals were

118 subjected to water and food fasting for $18 \mathrm{~h}$. Then, each ewe received $5 \mathrm{mmol}$ of

119 sodium 3-hydroxybutyrate $\left(\mathrm{C}_{4} \mathrm{H}_{7} \mathrm{NaO}_{3}, \geq 99.0 \%\right.$; Alfa Aesar®, Heysham, England) per

$120 \mathrm{~kg}$ of body weight in $360 \mathrm{~mL}$ fixed-volume solution with deionized water and $\mathrm{pH}$

121 adjusted to 7.4. Sodium 3-hydroxybutyrate varies from 191.5 to $335 \mathrm{mmol}$ according to

122 the ewe body weight. To ensure continuous infusion and better management of the

123 animals during the induction, a plastic catheter was implanted in the right jugular vein

124 (Intracat $^{\mathrm{TM}}$, Becton Dickinson and Company, NJ, USA). The protocol consisted of

125 intravenous infusion of BHB solution initially at a rate of $3 \mathrm{~mL}$ per minute, being adjusted

126 to ensure that the total BHB infusion time was 120 minutes for all animals.

127 During and after the infusion, blood was sampled through jugular venepuncture

128 at baseline (T1) before the infusion, and at 20, 40, 60, 80, 100 and 120 minutes (T2 to

129 T7) after the beginning of the induction. At the end of the infusion, six additional

130 samplings were performed after 15, 30, 60, 120, 180 and 240 minutes (T8 to T13). The

131 rectal temperature was measured with a digital thermometer at the same times

132 described above (Digital Thermometer Clinical Techline TS-101, São Paulo, SP, Brazil).

133 Animals were manually restrained for blood sampling. The induction model does not

134 produce pain or discomfort to the animals. Complete clinical evaluations to assure

135 animal welfare were done at each time-point, including all routine physical parameters 
136 and the ketone measurement in the urine using Combur-Test ${ }^{\circledR}$ (Roche Diagnostics,

137 Basel, Switzerland). During the study the environment temperature varies from 22 to 25 $138{ }^{\circ} \mathrm{C}$.

139

140

\section{BHB measurements}

141

In all the time-points two blood samples were obtained simultaneously. The first

142

one was used for measuring BHB in the HHM (Optium Xceed®; Abbott Laboratories,

143 São Paulo, SP, Brazil), using a disposable syringe of volume $3 \mathrm{~mL}$ that contained 0.1

$144 \mathrm{~mL}$ of sodium heparin. This sample was homogenized and a drop $( \pm 1.5 \mu \mathrm{L}$ of total

145 blood) was immediately placed on the reactive strip indicated for the device, which gave

146 the digital results in about 10 seconds (Panousis et al., 2012). The apparatus was

147 calibrated according to the manufacturer's recommendations. The principle for

148 measuring $\mathrm{BHB}$ in the HHM involves an enzyme-based electrochemical technique.

149 Briefly, when the blood sample is applied to the $\beta$-ketone test strip, the blood BHB

150 reacts with a chemical in the strip producing a small electrical current, which is

151 measured and the sensor displays a result (Anonymous, 2007).

152

Another blood sample of $4 \mathrm{~mL}$ was collected into tubes with a vacuum system

153 containing sodium fluoride and ethylenediaminetetraacetic acid as an anticoagulant

154 (Vacutainer ${ }^{\circledR}$, Becton Dickinson and Company, NJ, USA). These were homogenized by

155 repeatedly completely inverting immediately after collection and were kept under

156 refrigeration $\left(4^{\circ}\right.$ to $\left.6^{\circ} \mathrm{C}\right)$ for a maximum of two hours until they were processed. The

157 tubes were centrifuged for 10 minutes at $697 \mathrm{~g}$ to separate the plasma, which was then

158 stored at minus $20^{\circ} \mathrm{C}$ until analysis by an enzymatic colorimetric method (Williamson, 
159 Mellanby \& Krebs, 1962). Considering the induction protocol and the different collection 160 times, 247 samples were obtained (19 ewes; 13 collection times) with different BHB

161

162

163

164

165

166

167

168

169

170

171

172

173

174

175

176

177 GraphPad Prism software (GraphPad Inc., La Jolla, CA, USA) considering 5\% as

\section{Statistical analysis}

Data were analysed throughout the Shapiro-Wilks normality test. Agreement between the handheld meter and the reference enzymatic colorimetric method were assessed using Deming regression, Passing-Bablok regression and Bland-Altman difference plot. The later was used to determine the bias among the methods. Spearman rank correlation coefficient $(r)$ was calculated.

Two threshold values for blood BHB were established as indicatives of moderate (0.8 to $1.6 \mathrm{mmol} / \mathrm{L}$ ) and severe ( $\geq 1.6 \mathrm{mmol} / \mathrm{L})$ ketosis(Lacetera et al., 2001; Kulcsár et al., 2006; Balikci, Yildiz \& Gurdogan, 2009). Using the two abovementioned cut-offs for moderate and severe ketosis we were able to convert the BHB concentration to positive/negative results (separately for both severe and moderate ketosis) and establish the sensitivity and specificity, positive predictive value, negative predictive value, and accuracy of the handheld meter in relation to the gold-standard using classical epidemiological formulas (Smith, 1995). Statistical analysis was made with 178 significance level. 179

180 Results 
Although the sheep were subjected to induction of hyperketonaemia, none

182 presented clinical signs of PT, except intense ketonuria after 20 minutes of BHB

183 infusion to the end of this process. Table 2 presents the Passing-Bablok regression

184 analysis results. The overall mean \pm standard error (SE) value of BHB concentration

185 using the GS was $1.25 \pm 0.06 \mathrm{mmol} / \mathrm{L}$, while the $\mathrm{HHM}$ presented a higher mean of 1.90

$186 \pm 0.01(\mathrm{SE}) \mathrm{mmol} / \mathrm{L}$. The BHB concentration of the GS ranged from 0.11 to 3.94

$187 \mathrm{mmol} / \mathrm{L}$, while the results of the $\mathrm{HHM}$ ranged from 0.10 to $7.10 \mathrm{mmol} / \mathrm{L}$. Figure 1

188 presents the Deming regression analysis between concentrations of BHB measured by

189 the two methods. The results from the HHM can be corrected according to the GS

190 through the equation $\mathrm{HHM}=-0.19+1.69 \times \mathrm{GS}$, according to the Passing-Bablok

191 regression analysis $(r=0.984)$.

192

Figure 2 presents the Bland-Altman plot of the difference between BHB

193 measured both methods (HHM minus GS) against the mean. The HHM results showed

194 a bias of $0.65 \pm 0.71$ (SD) $\mathrm{mmol} / \mathrm{L}(-0.74$ to $2.0495 \%$ limits of agreement). Figure 3

195 presents two Bland-Altman plots, the first one included samples with BHB values below

$1961.6 \mathrm{mmol} / \mathrm{L}$, indicative of moderate ketosis but excluding the higher BHB values. The

197 second plot considered only samples with $\mathrm{BHB}$ values below $0.8 \mathrm{mmol} / \mathrm{L}$, indicative of

198 physiological BHB values(Lacetera et al., 2001; Balikci, Yildiz \& Gurdogan, 2009).

199 When values were stratified the bias was reduced to $0.275 \pm 0.38$ (SD) $\mathrm{mmol} / \mathrm{L}(-0.47$ to

$2001.0295 \%$ limits of agreement) for data excluding high BHB values and to $0.11 \pm 0.21$

201 (SD) $\mathrm{mmol} / \mathrm{L}$ (-0.31 to $0.5295 \%$ limits of agreement) for normal $\mathrm{BHB}$ range.

202 Table 3 evaluates the diagnostic result (positive or negative) from blood BHB

203 concentration measured by HHM and GS method that will be indicative of moderate 
204 ketosis. Additionally, Cohen's kappa coefficient of agreement between tests is 205 presented. For diagnostic of moderate ketosis, the HHM presented 19 false-positive and 2063 false-negative results, whereas for severe ketosis diagnose, 41 false-positive and 1 207 false-negative, in comparison to GS. It is noteworthy that the ketonemia induction model 208 resulted in 52 samples (21\%) with BHB concentration above $3.0 \mathrm{mmol} / \mathrm{L}$.

209 The rectal temperature increased (Figure 4) as the BHB infusion started and kept 210 higher as compared to the pre-infusion time. The mean rectal temperature at the 211 selected time points where we observed false-positive results for the severe ketosis $212\left(n=41 ; 38.9 \pm 0.6^{\circ} \mathrm{C}\right)$ were higher when compared to the baseline $\left(n=24 ; 38.5 \pm 0.8^{\circ} \mathrm{C}\right)$ $213(P<0.05)$.

214

215 Discussion

216 The infusion of BHB solution caused a rapid increase in the BHB blood

217 concentration values that were sustainably high throughout the infusion period and

218 decreasing continuously thereafter. Nevertheless, as the blood concentration surpasses

$2191.0 \mathrm{mmol} / \mathrm{L} \mathrm{BHB}$, the renal threshold, an intense ketonuria collaborate to decrease or to 220 avoid an extreme hyperketonaemia in the blood.

221 The current model of induction of hyperketonaemia produced greater number of 222 samples $(n=52 ; 21 \%$ ) with blood $B H B$ values higher than $3.0 \mathrm{mmol} / \mathrm{L}$ measured by HHM 223 than those obtained by other authors: 18 out 193 (9.32\%) (Panousis et al., 2012) and 8 224 out 465 (1.72\%) (Hornig et al., 2013), being the later, the study that validated the HHM 225 for sheep. The presence of more samples with higher blood BHB concentration turn the 226 validation of the HHM more reliable than those carried out in other early studies. 
Although there are previous literature regarding the use of handheld meter in

228 dairy cow, they were performed with healthy animals (Nielen et al., 1994; Carrier et al.,

229 2004; Kupczyński \& Cupok, 2007), thus, resulting in limited data of affected animals (i.e.

230 animals with moderate or severe ketosis). In sheep, similar studies evaluated healthy

231 animals (Firat \& Özpinar, 2002; Panousis et al., 2012) and one study used feed

232 restriction in late gestation to increase blood BHB concentration (Cal-Pereyra et al.,

233 2015a). No previous studies used our BHB-infusion methodology, which resulted in a

234 higher number of animals with increased blood BHB and therefore a more robust

235 dataset for sensitivity and specificity analysis. Additionally, our study is the first report

236 using Brazilian beef breed (Santa-Inês) at tropical conditions.

237 Overall mean BHB concentration was higher in the HHM than the GS $(P<0.05)$.

238 These results were different from those recorded by previous reports (Panousis et al.,

239 2012; Hornig et al., 2013) that described a similar or greater mean values for BHB

240 measured by GS than HHM. Previous studies with cattle show that the difference

241 between HHM and GS enlarged as the BHB levels were higher than $3.0 \mathrm{mmol} / \mathrm{L}$

242 (Megahed et al., 2017). As in the current experiment, a reasonable amount of the blood

243 samples $(21 \%)$ surpass $3.0 \mathrm{mmol} / \mathrm{L}$ of $\mathrm{BHB}$, this could increase the difference of the

244 overall means obtained by HHM and GS. This difference could interfere with the results

245 since there was a strong positive correlation $(r=0.99)$ and a high sensibility $(0.99)$,

246 negative predictive values (0.99) and accuracy (0.87).

247 Using the $\mathrm{HHM}$ for the diagnostic of $\mathrm{BHB}$ concentration indicative of moderate

248 ketosis $(0.8-1.6 \mathrm{mmol} / \mathrm{L})$ when compared with GS, we found a high sensitivity $(0.98)$ and

249 specificity (0.81) and a perfect agreement at Kappa test, similarly as previous reports 
250 with healthy animals (Dawson, Carson \& Kilpatrick, 1999; Voyvoda \& Erdogan, 2010;

251 Panousis et al., 2012; Pineda \& Cardoso, 2015; Macmillan et al., 2017). Using the HHM

252 for the diagnosis of blood $\mathrm{BHB}$ concentration indicative of severe ketosis $(\mathrm{BHB} \geq 1.6$

$253 \mathrm{mmol} / \mathrm{L}$ ), only one false-negative case was detected indicating that $\mathrm{HHM}$ has a very

254 high sensitivity (0.99). On the other hand, we found 41 false-positive results suggesting

255 that decreased somehow the specificity $(0.75)$. The methods had a substantial

256 agreement at Kappa test. Conversely, previous reports (Panousis et al., 2012; Hornig et

257 al., 2013) using the same equipment obtained very high specificity.

258 According to Iwersen et al. (2013) and Megahed et al. (2017) the higher the

259 blood temperature, the greater is the BHB concentration measure by HHM. The rectal

260 temperature increased as the BHB infusion started and kept high as compared to the

261 pre-infusion time. Most of the false-positive results occurred within the first 60 min of

262 infusion and between 15 to 60 min post-infusion when the BHB blood concentration was

263 increasing and decreasing, respectively. By these times the rectal temperature

264 increased as well, probably by a small quantity of pyrogen in the solution that caused a

265 short and slight hyperthermia. According to Bligh (1957), there is a very high positive

266 correlation between rectal and blood temperature. Thus, in the early ascending and

267 descending curve when the BHB blood levels were between 1.0 and $1.5 \mathrm{mmol} / \mathrm{L}$,

268 measured by GS, most of the false-positive samples had values superior to $1.6 \mathrm{mmol} / \mathrm{L}$

269 probably caused by higher blood temperature.

270

271 Conclusion 
272 An overview of the results within the different ranges of $\beta$-hydroxybutyrate acid

273 permits to affirm that handheld meter is sufficiently accurate and sensible to detect

274 hyperketonaemia in sheep, which recommends its use to provide reliable, rapid, ewe-

275 side early diagnosis of pregnancy toxaemia in sheep. This was this first study to validate

276 this equipment in tropical conditions.

277

278 Ethics statement

279 This research was approved by the Committee on the Ethics of Animal Experiments of 280 the School of Veterinary Medicine and Animal Science, University of São Paulo. All 281 animals were treated with high standard (best practice) of veterinary care and with 282 animal welfare.

283

\section{References}

285 Anonymous. 2007. User's Guide Blood Glucose Monitoring System. :34.

286 Araújo CASC, Rodrigues FAML, Trivelatto BF, dos Reis LF, Mori CS, Ortolani EL,

287 Minervino AHH. 2014. Clinical evaluation of nervous ketosis induced by

288 isopropanol in sheep. Brazilian Journal of Veterinary Research and Animal Science

289 50:493-496. DOI: 10.11606/issn.1678-4456.v50i6p493-496.

290 Araújo CASC, Sousa RS, Monteiro BM, Oliveira FLC, Minervino AHH, Rodrigues FAML, 291 Vale RG, Mori CS, Ortolani EL. 2018. Potential prophylactic effect of recombinant 292 bovine somatotropin (rbST) in sheep with experimentally induced hyperketonemia. 293 Research in Veterinary Science 119:215-220. DOI: 10.1016/j.rvsc.2018.06.005.

294 Balikci E, Yildiz A, Gurdogan F. 2009. Investigation on Some Biochemical and Clinical 

Veterinary Advances 8:1268-1273.

Benedet, Franzoi, Manuelian, Penasa, De Marchi. 2020. Variation of Blood Metabolites of Brown Swiss, Holstein-Friesian, and Simmental Cows. Animals 10:271. DOI: 10.3390/ani10020271.

Bligh J. 1957. The relationship between the temperature in the rectum and of the blood in the bicarotid trunk of the calf during exposure to heat stress. The Journal of physiology 136:393-403.

Cal-Pereyra L, Benech A, González-Montaña J, Acosta-Dibarrat J, Da Silva S, Martín A. 2015a. Changes in the metabolic profile of pregnant ewes to an acute feed restriction in late gestation. New Zealand Veterinary Journal 63:141-146. DOI: 10.1080/00480169.2014.971083.

Cal-Pereyra L, González-Montaña JR, Benech A, Acosta-Dibarrat J, Martín M, Perini S, Abreu M, Da Silva S, Rodríguez P. 2015b. Evaluation of three therapeutic alternatives for the early treatment of ovine pregnancy toxaemia. Irish Veterinary Journal 68:25. DOI: 10.1186/s13620-015-0053-2.

Carrier J, Stewart S, Godden S, Fetrow J, Rapnicki P. 2004. Evaluation and use of three cowside tests for detection of subclinical ketosis in early postpartum cows. Journal of Dairy Science 87:3725-3735. DOI: 10.3168/jds.S0022-0302(04)735110.

Dawson LER, Carson AF, Kilpatrick DJ. 1999. The effect of the digestible undegradable protein concentration of concentrates and protein source offered to ewes in late pregnancy on colostrum production and lamb performance. Animal Feed Science 
and Technology 82:21-36. DOI: 10.1016/S0377-8401(99)00101-7.

319 Firat A, Özpinar A. 2002. Metabolic profile of pre-pregnancy, pregnancy and early

320 lactation in multiple lambing Sakiz ewes: 1. Changes in plasma glucose, 3-

321 hydroxybutyrate and cortisol levels. Annals of Nutrition and Metabolism 46:57-61.

$322 \quad$ DOI: $10.1159 / 000057641$.

323 Hoenig M, Dorfman M, Koenig A. 2008. Use of a hand-held meter for the measurement 324 of blood beta-hydroxybutyrate in dogs and cats. Journal of Veterinary Emergency 325 and Critical Care 18:86-87. DOI: 10.1111/j.1476-4431.2007.00252.x.

326 Hornig KJ, Byers SR, Callan RJ, Holt T, Field M, Han H. 2013. Evaluation of a point-of-

$327 \quad$ care glucose and $\beta$-hydroxybutyrate meter operated in various environmental 328 conditions in prepartum and postpartum sheep. American Journal of Veterinary 329 Research 74:1059-1065. DOI: 10.2460/ajvr.74.8.1059.

330 Iwersen M, Klein-Jöbstl D, Pichler M, Roland L, Fidlschuster B, Schwendenwein I, 331 Drillich M. 2013. Comparison of 2 electronic cowside tests to detect subclinical 7121.

Kalyesubula M, Rosov A, Alon T, Moallem U, Dvir H. 2019. Intravenous Infusions of 336 Glycerol Versus Propylene Glycol for the Regulation of Negative Energy Balance in Sheep: A Randomized Trial. Animals 9:731. DOI: 10.3390/ani9100731.

Kaneko JJ, Harvey JW, Bruss ML. 2008. Clinical Biochemistry of Domestic Animals.

Kulcsár M, Dankó G, Magdy HGI, Reiczigel J, Forgach T, Proháczik A, Delavaud C, Magyar K, Chilliard Y, Solti L, Huszenicza G. 2006. Pregnancy stage and number 
341 of fetuses may influence maternal plasma leptin in ewes. Acta Veterinaria

$342 \quad$ Hungarica 54:221-234. DOI: 10.1556/AVet.54.2006.2.9.

343 Kupczyński R, Cupok A. 2007. Sensitivity and specificity of various tests determining $\beta$ -

344 hydroxybutyrate acid in diagnosis of ketosis in cows. Electronic Journal of Polish

$345 \quad$ Agricultural Universities 10:\#15.

346 Lacetera N, Bernabucci U, Ronchi B, Nardone A. 2001. Effects of subclinical pregnancy

347 toxemia on immune responses in sheep. American journal of veterinary research

$348 \quad 62: 1020-4$.

349 Macmillan K, López Helguera I, Behrouzi A, Gobikrushanth M, Hoff B, Colazo MG.

350 2017. Accuracy of a cow-side test for the diagnosis of hyperketonemia and

351 hypoglycemia in lactating dairy cows. Research in Veterinary Science 115:327-

$352 \quad 331$. DOI: $10.1016 / j . r v s c .2017 .06 .019$.

353 Megahed AA, Hiew MWH, Townsend JR, Constable PD. 2017. Characterization of the 354 analytic performance of an electrochemical point-of-care meter for measuring $\beta$ -

355 hydroxybutyrate concentration in blood and plasma from periparturient dairy cattle.

$356 \quad$ Veterinary Clinical Pathology 46:314-325. DOI: 10.1111/vcp.12493.

357 Nielen M, Aarts M, Jonkers A, Wensing T, Schukken Y. 1994. Evaluation of two

358 cowside tests for the detection of subclinical ketosis in dairy cows. Canadian

$359 \quad$ Veterinary Journal 35:229-232.

360 Ortolani EL, Benesi FJ. 1989. Ocorrência de toxemia da prenhez em cabras (Capra

361 hircus, L) e ovelhas (Ovis aries, L) criadas no Estado de São Paulo, Brasil. Revista

362 da Faculdade de Medicina Veterinária e Zootecnia da Universidade de São Paulo

363 26:229. DOI: 10.11606/issn.2318-3659.v26i2p229-234. 
364 Panousis N, Brozos C, Karagiannis I, Giadinis ND, Lafi S, Kritsepi-Konstantinou M. 365 2012. Evaluation of Precision $X c e e d \AA$ meter for on-site monitoring of blood $\beta$ 366 hydroxybutyric acid and glucose concentrations in dairy sheep. Research in 368 Veterinary Science 93:435-439. DOI: 10.1016/j.rvsc.2011.06.019.

Pineda A, Cardoso FC. 2015. Technical note: Validation of a handheld meter for measuring $\beta$-hydroxybutyrate concentrations in plasma and serum from dairy cows.

371 Radostits OM, Gay CC, Hinchcliff KW, Constable PD. 2007. Veterinary medicine: a textbook of the diseases of cattle, sheep, pigs, goats, and horses. Saunders Elsevier.

374 375 376 377 378

379 380 381 382 Journal of Dairy Science 98:8818-8824. DOI: 10.3168/jds.2015-9667.

\section{Elsevier.}

Schlumbohm C, Harmeyer J. 2003. Hypocalcemia Reduces Endogenous Glucose

Production in Hyperketonemic Sheep. Journal of Dairy Science 86:1953-1962.

DOI: $10.3168 / j \mathrm{jds} . S 0022-0302(03) 73783-7$.

Scott PR, Sargison ND, Penny CD, Pirie RS, Kelly JM. 1995. Cerebrospinal fluid and plasma glucose concentrations of ovine pregnancy toxaemia cases, inappetant ewes and normal ewes during late gestation. The British veterinary journal 151:3944.

Smith RD. 1995. Veterinary clinical epidemiology: a problem-oriented approach. Boca Raton: CRC Press.

Voyvoda H, Erdogan H. 2010. Use of a hand-held meter for detecting subclinical ketosis in dairy cows. Research in Veterinary Science 89:344-351. DOI:

10.1016/j.rvsc.2010.04.007.

Williamson DH, Mellanby J, Krebs HA. 1962. Enzymic determination of D(-)-beta- 
387 hydroxybutyric acid and acetoacetic acid in blood. The Biochemical journal 82:903886.

389

390 
392 Figure captions

393 Figure 1. Deming regression analysis between concentrations of $\beta$-hydroxybutyrate

394 (BHB) blood measured by handheld meter ( $\mathrm{HHM}$ ) and gold-standard colorimetric

395 method (GS) $(n=247)$. The blue line indicates the regression line and the orange line

396 denotes the identity line $(x=y)$. Deming regression: $H H M=-0.29+1.75 G S(n=247)$.

397 Pearson correlation coefficient $r=0.996$.

398

399 Figure 2. Bland-Altman plot of the difference between $\beta$-hydroxybutyrate (BHB)

400 measured by the handheld electrochemical meter and the BHB measured using the

401 gold-standard colorimetric method against the mean BHB for both methods. The solid

402 horizontal line is the mean bias $(0.65 \mathrm{mmol} / \mathrm{L})$ and the 2 horizontal dashed lines

403 represent the 95\% Confidence Interval for agreement.

404

405 Figure 3. (A) Bland-Altman plot considering only BHB values below $1.6 \mathrm{mmol} / \mathrm{L}$

$406(n=162)$ of the difference between $\beta$-hydroxybutyrate (BHB) measured by the handheld

407 electrochemical meter and the BHB measured using the gold-standard colorimetric

408 method against the mean BHB for both methods. The solid horizontal line is the mean

409 bias $(0.27 \mathrm{mmol} / \mathrm{L})$ and the 2 horizontal dashed lines represent the $95 \%$ Confidence

410 Interval ( $\mathrm{Cl})$ for agreement. (B) Bland-Altman plot considering only BHB values below

$4110.8 \mathrm{mmol} / \mathrm{L}(\mathrm{n}=101)$ of the difference between BHB measured by the handheld

412 electrochemical meter and the BHB measured using the gold-standard colorimetric

413 method against the mean BHB for both methods. The solid horizontal line is the mean 
414 bias $(0.11 \mathrm{mmol} / \mathrm{L})$ and the 2 horizontal dashed lines represent the $95 \% \mathrm{Cl}$ for 415 agreement.

416 Figure 4. Mean and standard error of the mean values of the rectal temperature $\left({ }^{\circ} \mathrm{C}\right)$ 417 during the experiment. $\beta$-hydroxybutyrate infusion stared at T2 and finished at T7. 418 
Figure 1

Figure 1

Figure 1. Deming regression analysis between concentrations of $\beta$-hydroxybutyrate (BHB) blood measured by handheld meter (HHM) and gold-standard colorimetric method (GS) $(n=247)$. The blue line indicates the regression line and the orange line denotes the identity line $(x=y)$. Deming regression: HHM $=-0.29+1.75$ GS $(n=247)$. Pearson correlation coefficient $r=0.996$.

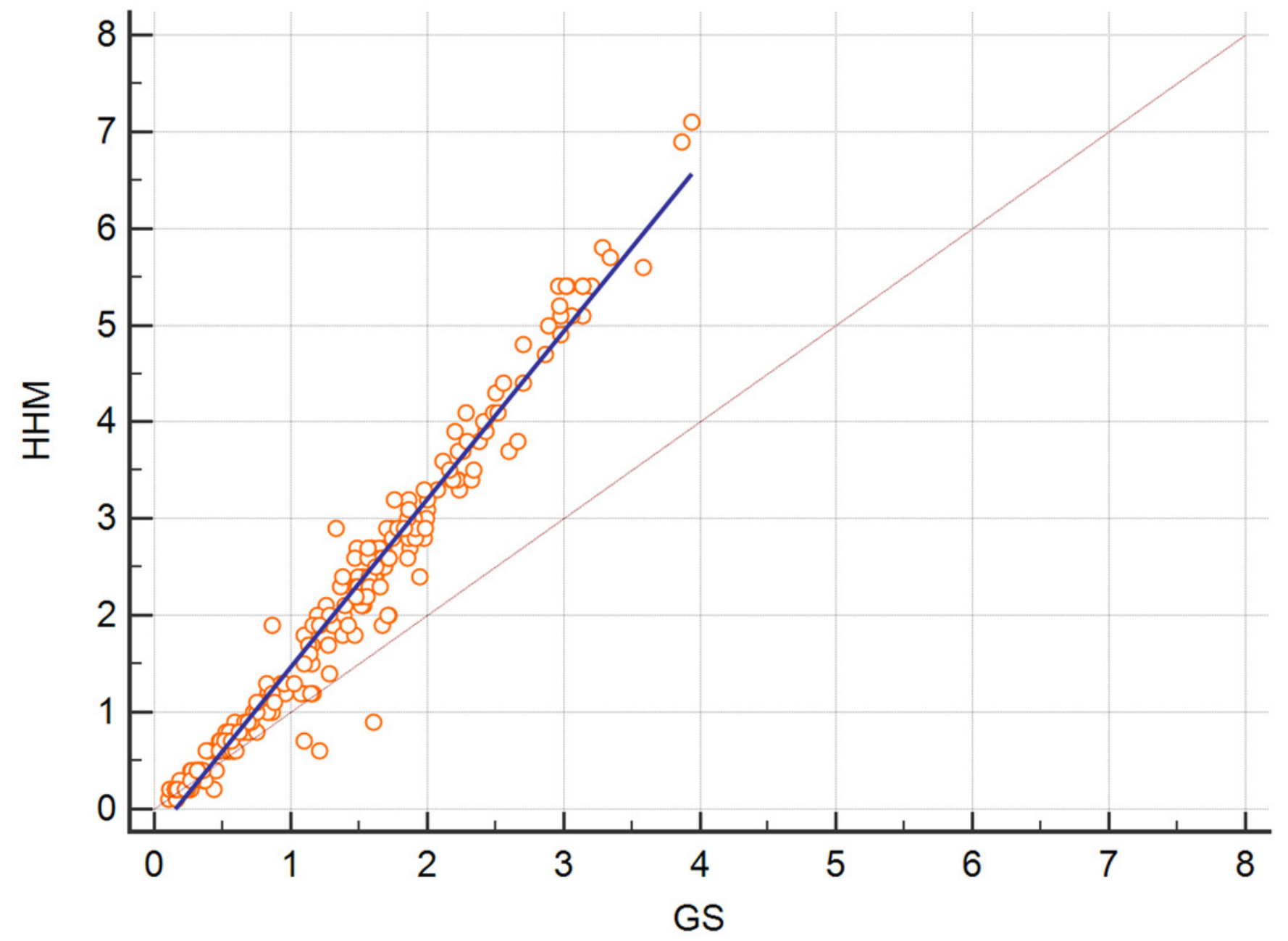


Figure 2

Figue 2

Bland-Altman plot of the difference between BHB measured by the handheld electrochemical meter and the BHB measured using the gold-standard colorimetric method against the mean BHB for both methods. The solid horizontal line is the mean bias $(0.65 \mathrm{mmol} / \mathrm{L})$ and the 2 horizontal dashed lines represent the $95 \% \mathrm{Cl}$ for agreement.

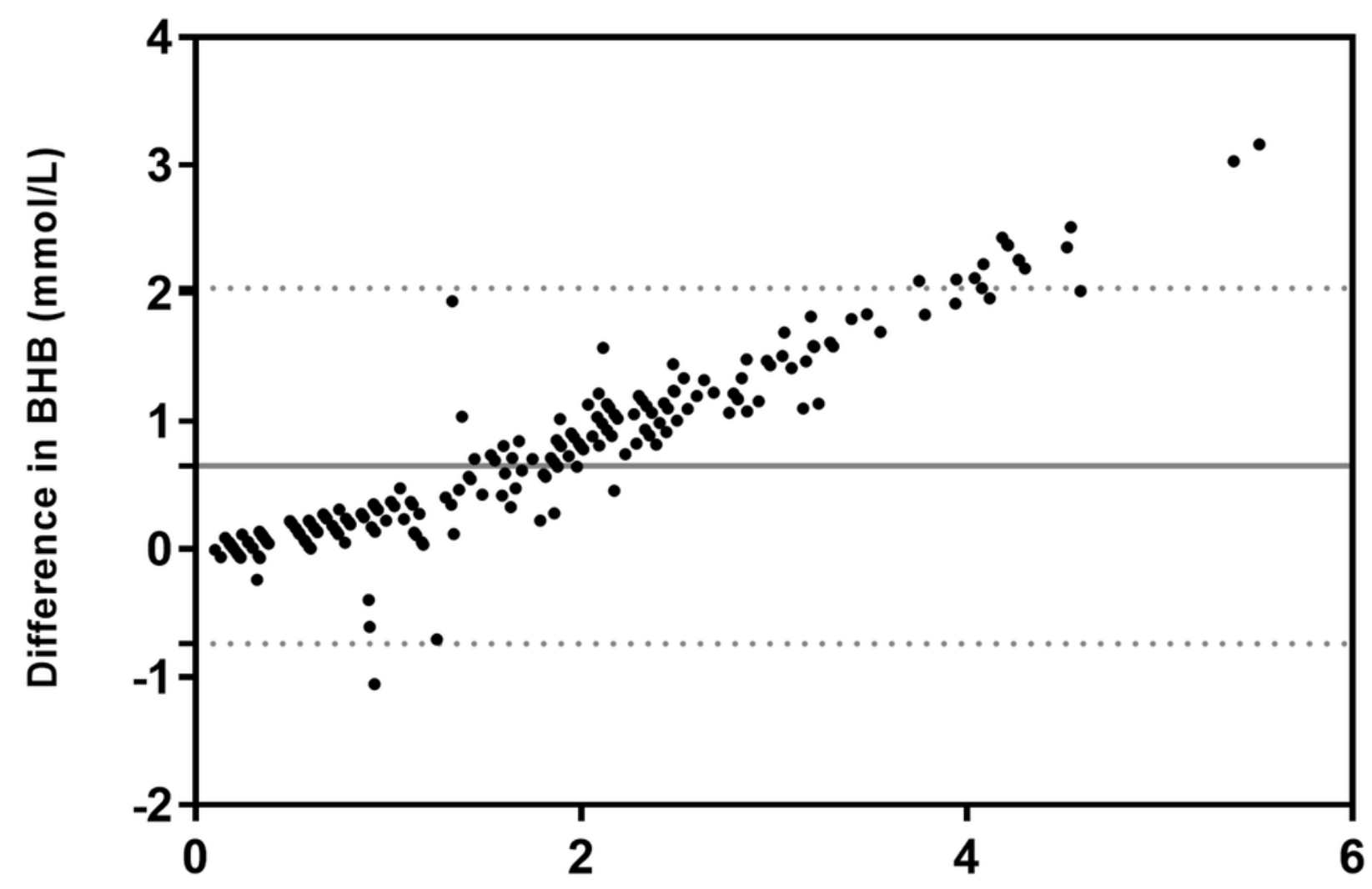

Mean BHB concentration ( $\mathrm{mmol} / \mathrm{L}$ ) 


\section{Figure 3}

Figure 3.

Figure 3. (A) Bland-Altman plot considering only BHB values below $1.6 \mathrm{mmol} / \mathrm{L}(n=162)$ of the difference between $\beta$-hydroxybutyrate $(\mathrm{BHB})$ measured by the handheld electrochemical meter and the BHB measured using the gold-standard colorimetric method against the mean BHB for both methods. The solid horizontal line is the mean bias $(0.27 \mathrm{mmol} / \mathrm{L})$ and the 2 horizontal dashed lines represent the 95\% Confidence Interval (CI) for agreement. (B) Bland-Altman plot considering only BHB values below $0.8 \mathrm{mmol} / \mathrm{L}(n=101)$ of the difference between $\mathrm{BHB}$ measured by the handheld electrochemical meter and the BHB measured using the gold-standard colorimetric method against the mean BHB for both methods. The solid horizontal line is the mean bias $(0.11 \mathrm{mmol} / \mathrm{L})$ and the 2 horizontal dashed lines represent the $95 \% \mathrm{Cl}$ for agreement.
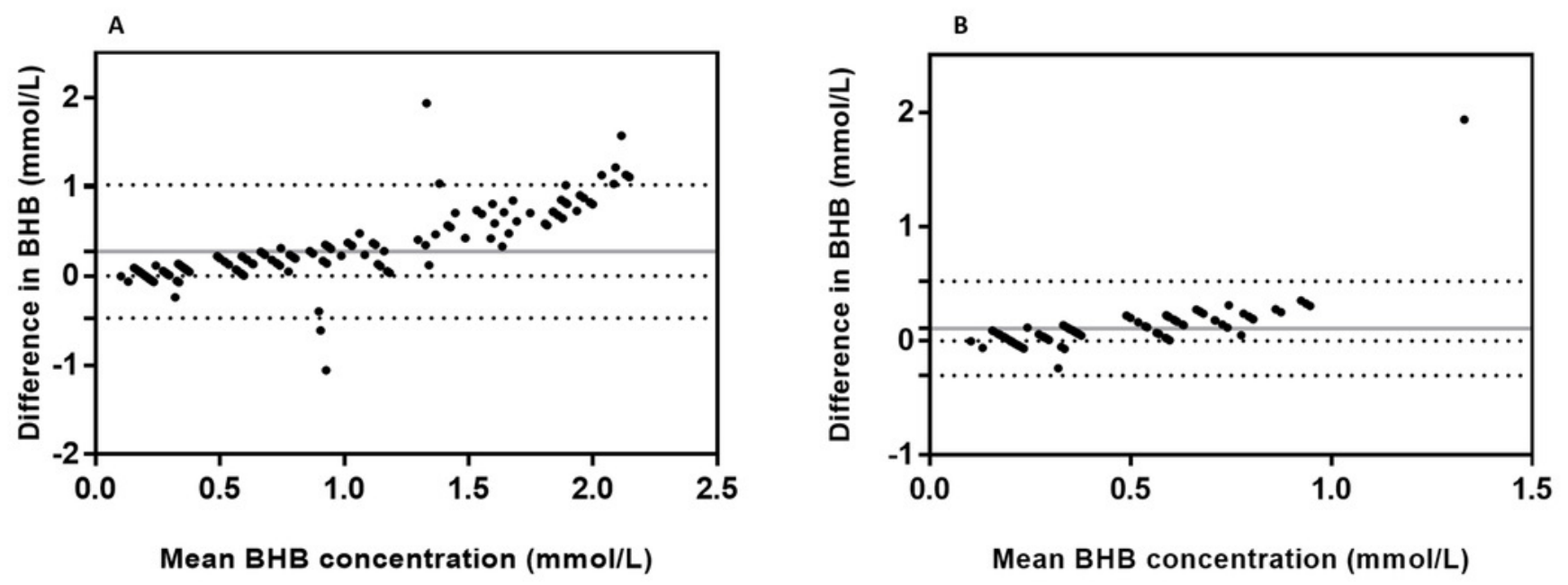
Figure 4

Figure 4

Figure 4. Mean values and standard error of rectal temperature $\left({ }^{\circ} \mathrm{C}\right)$ during the experiment. $\beta$-hydroxybutyrate infusion stared at T2 and finished at T7.

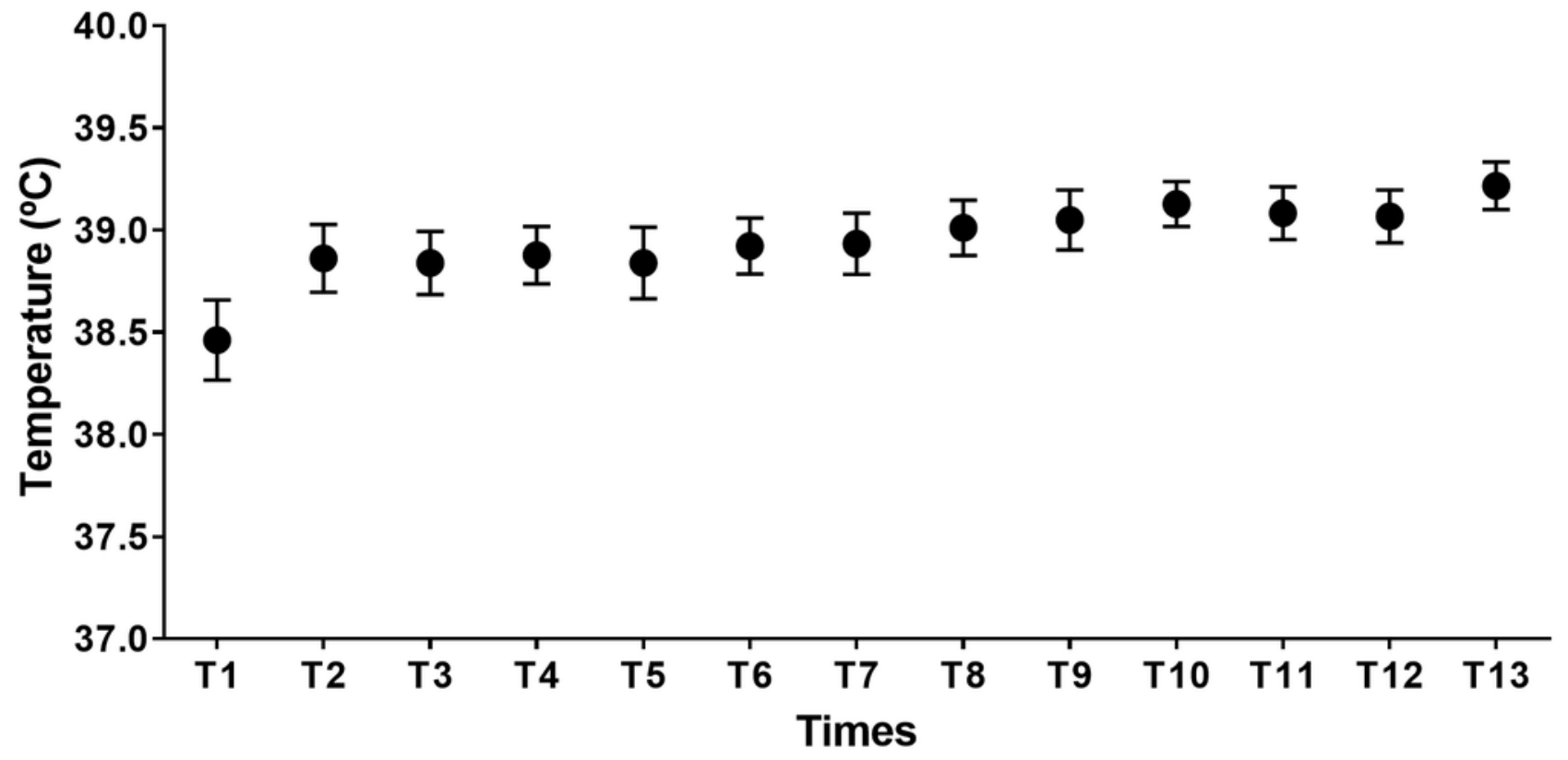




\section{Table $\mathbf{1}$ (on next page)}

Table 1

Chemical composition of diet (hay and concentrate) used during the experiment. 
1 Table 1. Chemical composition of the diet (hay and concentrate) used during the

2 experiment. Crude protein, neutral detergent fibre, ether extract and ash were

3 calculated on a dry matter basis.

\begin{tabular}{lcc}
\hline Parameters & Coast-cross hay & Concentrate \\
\hline Dry matter (\%) & 84.1 & 87.0 \\
Crude protein (\%) & 7.5 & 14.0 \\
Neutral detergent fibre (\%) & 33.1 & 16.0 \\
Ether extract (\%) & 1.9 & 2.0 \\
Ash (\%) & 6.1 & 16.0 \\
\hline
\end{tabular}

4 


\section{Table 2 (on next page)}

Table 2

Passing-Bablok regression analysis comparing the handheld meter (HHM) and the gold-standard (GS) enzymatic colorimetric test.

Cl: confidence interval. 
1 Table 2. Passing-Bablok regression analysis comparing the handheld meter (HHM)

2 and the gold-standard (GS) enzymatic colorimetric test.

\begin{tabular}{|c|c|c|}
\hline Parameters & $\begin{array}{c}\text { GS enzymatic } \\
\text { colorimetric method } \\
(\mathrm{mmol} / \mathrm{L})\end{array}$ & $\begin{array}{l}\text { Handheld meter } \\
(\mathrm{mmol} / \mathrm{L})\end{array}$ \\
\hline Lowest value & 0.11 & 0.10 \\
\hline Highest value & 3.94 & 7.10 \\
\hline Arithmetic mean & 1.25 & 1.90 \\
\hline Median & 1.16 & 1.70 \\
\hline Standard deviation & 0.89 & 1.56 \\
\hline Standard error of the mean & 0.057 & 0.099 \\
\hline Regression Equation & \multicolumn{2}{|c|}{$\mathrm{HHM}=-0.19+1.69 \mathrm{GS}$} \\
\hline \multicolumn{3}{|l|}{ Systematic differences } \\
\hline Intercept A & \multicolumn{2}{|l|}{-0.187} \\
\hline $95 \% \mathrm{Cl}$ & \multicolumn{2}{|l|}{-0.215 to -0.162} \\
\hline \multicolumn{3}{|l|}{ Proportional differences } \\
\hline Slope B & \multicolumn{2}{|l|}{1.691} \\
\hline $95 \% \mathrm{Cl}$ & \multicolumn{2}{|l|}{1.657 to 1.724} \\
\hline \multicolumn{3}{|l|}{ Random differences } \\
\hline Residual Standard Deviation (RSD) & \multicolumn{2}{|l|}{0.137} \\
\hline \pm 1.96 RSD Interval & \multicolumn{2}{|l|}{-0.268 to 0.268} \\
\hline \multicolumn{3}{|l|}{ Linear model validity } \\
\hline Cusum test for linearity & \multicolumn{2}{|c|}{ Significant deviation from linearity $(P<0.01)$} \\
\hline \multicolumn{3}{|l|}{ Spearman rank correlation coefficient } \\
\hline Correlation coefficient & \multicolumn{2}{|l|}{0.984} \\
\hline Significance level & \multicolumn{2}{|l|}{$P<0.0001$} \\
\hline $95 \% \mathrm{Cl}$ & \multicolumn{2}{|l|}{0.979 to 0.987} \\
\hline
\end{tabular}

3 Cl: confidence interval. 


\section{Table 3 (on next page)}

Table 3

Diagnostic results (positive or negative) from blood $\beta$-hydroxybutyrate (BHB) concentration measured by handheld meter and gold-standard colorimetric method indicative of moderate ketosis (BHB 0.8-1.6 mmol/L) or for severe ketosis (BHB $\geq 1.6 \mathrm{mmol} / \mathrm{L}$ ). 
1 Table 3. Diagnostic results (positive or negative) from blood $\beta$-hydroxybutyrate (BHB)

2 concentration measured by handheld meter and gold-standard colorimetric method

3 indicative of moderate ketosis (BHB 0.8-1.6 mmol/L) or for severe ketosis (BHB $\geq 1.6$

$4 \mathrm{mmol} / \mathrm{L})$.

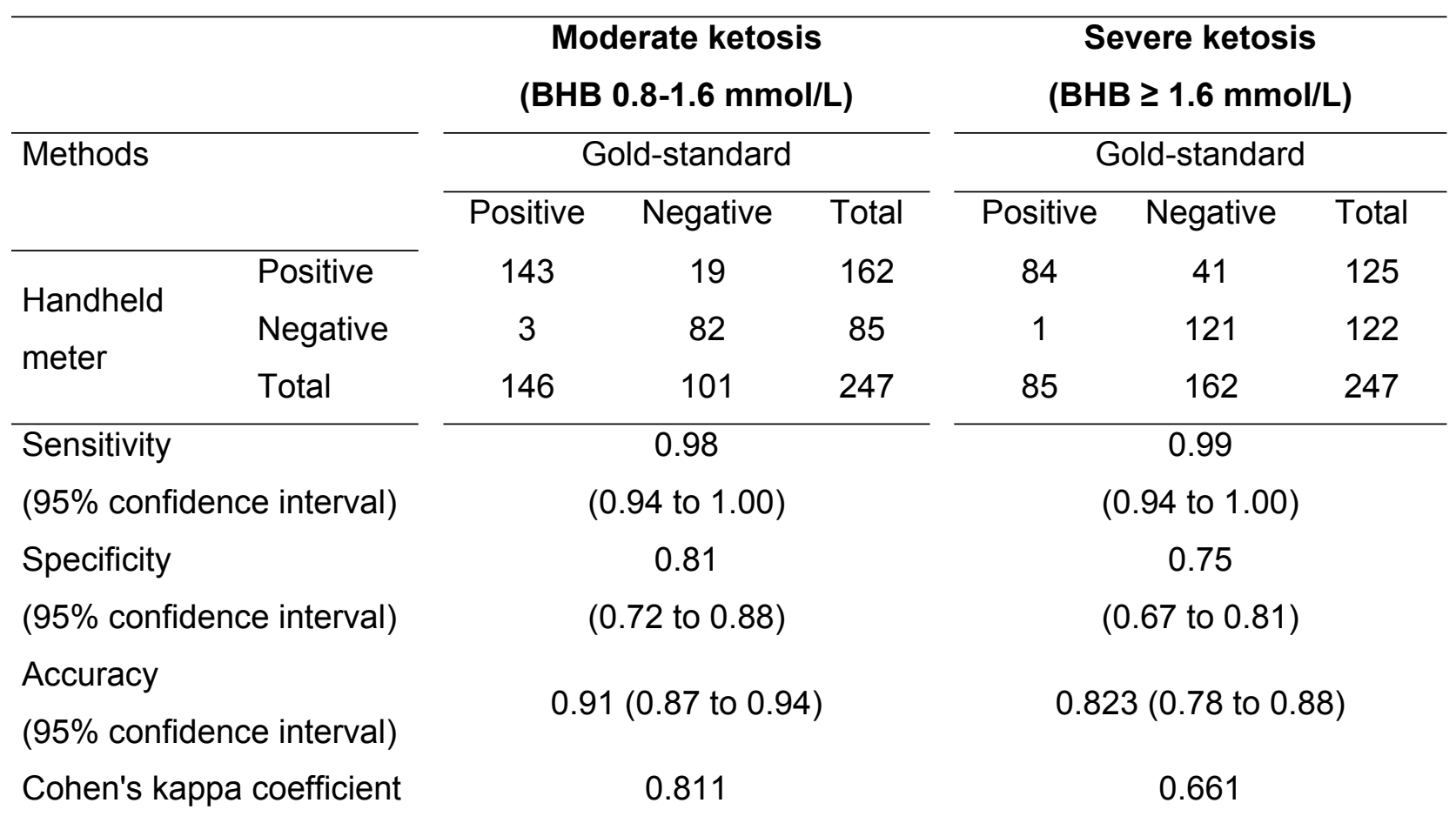

5

6 